\title{
Zum Tod von Andreas Kuhlmann
}

A m 6. Februar 2009 starb Andreas Kuhlmann. Dass er mit seiner Lebenssituation nicht mehr weiterleben konnte, erfüllt uns mit tiefer Trauer. Er setzte seinem Leben ein Ende von eigener Hand.

Andreas Kuhlmann studierte in Bielefeld und wurde in Philosophie promoviert. Er arbeitete seit vielen Jahren in Frankfurt als freier Publizist. In der deutschen Bioethik war Andreas Kuhlmann eine sichtbare Erscheinung. Seine Beiträge zu Fragen von Schwangerschaftsabbruch, Sterbehilfe, genetischer Frühdiagnostik und Diskriminierung von Menschen mit Behinderungen waren Referenzpunkte des bioethischen und biopolitischen Diskurses. Seine Texte und Positionen haben eine sehr eigene Signatur und entziehen sich gängigen Zuordnungen. Unprätentiös geschrieben, zugänglich in der Sprache, sind sie zugleich differenziert und sicher im Urteil. Seine Analysen des biopolitischen Diskurses verschieben gängige Frontstellungen und Oppositionen. Sie sind nie nur politische Stellungnahmen sondern stets subtile philosophische und soziologische Analysen.

Als die Akademie für Ethik in der Medizin vor einigen Jahren begann, sich intensi- ver mit dem Verhältnis zwischen Medizinethik und Behindertenbewegung $\mathrm{zu}$ beschäftigen, wurde Andreas Kuhlmann auch in der Akademie eine Figur von zentraler Bedeutung. Er analysierte die Dynamik von Diskriminierungen und die Analyse der Verletzungen von Menschen mit Behinderungen subtiler als im Diskurs üblich. Dabei ging es zumeist auch um die Selbstinterpretationen und Selbstmissverständnisse der Behindertenbewegung und um die Verleugnung von Leiden. Das hat ihm nicht nur Freunde eingebracht. Dabei hat er nie die eigene Behinderung zum Garant für die Triftigkeit der vertretenen Position herangezogen, vielmehr speist sich die Überzeugungskraft seiner Texte aus der Klarheit und Prägnanz der Analyse.

Menschlich hat Andreas Kuhlmann diejenigen, die ihn erleben durften, immer beeindruckt. Unvergesslich sind sein Engagement im Gespräch, sein unaufgeregtes Auftreten und sein Lachen. Die deutsche Bioethik verliert mit Andreas Kuhlmann einen ebenso klugen wie eindrucksvollen Vertreter ihres Faches und einen liebenswerten Menschen.

Marcus Düwell 